\title{
O comum mediático e o pertencimento nas práticas de recepção em comunicação
}

\begin{abstract}
Resumo
$O$ tema do sentimento de pertencimento, cada vez mais presente sob diferentes ângulos disciplinares no estudo da relação entre comunidade e a sociedade contemporânea globalizada, também vem se evidenciando no âmbito de práticas e estudos de comunicação social. É um tema que sinaliza quanto às novas formas e intensidades de manifestação de uma sociedade que amplia exclusões e desigualdades, expressando a crise contemporânea de pertencimento a um comum aglutinador. $\mathrm{O}$ presente texto busca aproximações sobre a pertinência e a fundamentação do tema e de suas sinalizações em tradições de estudo a respeito, indagando em específico quanto ao comum que motivaria a necessidade do sentimento de pertencimento e quanto às mediações significadas pela comunicação mediática.
\end{abstract}

\section{Introdução}

A relação entre indivíduo e sociedade é desde sempre objeto nuclear de indagações das ciências humanas e sociais tanto quanto é empiricamente por onde tensões e desafios os mais diversos fazem dessa mesma relação uma fonte permanente de conflitos. O eu e o outro, o individual e o coletivo, têm ocupado a história e a busca de um ponto de encontro. A presença constante das temáticas da inclusão e da exclusão social, da emancipação, do pertencimento, da cidadania, da identidade e da diferença em diferentes ângulos de compreensão da sociedade contemporânea sinaliza igualmente a presença de tensões e conflitos como linguagens dos desencontros ainda hoje entre o indivíduo e a sociedade.

São questões conceituais e teóricas permeando o mundo da pesquisa cientifica em diferentes áreas disciplinares de seu desenvolvimento, mas são também questões concretas traduzidas não tanto em processos de mudanças sócio-econômicas de âmbito estrutural e revolucionário, mas são visíveis em práticas de movimentos sociais e de ongs, de comunidades e grupos políticos e culturais indicando descrença em utopias até então vigentes, rejeição ao processo de dominação, à fragmentação do sujeito, às crises do Estado, à heterogeneidade e a pluralidade das formas do ser e do ter, do crer e do viver, enfim, do estar junto social. São manifestações práticas sinalizando uma sociedade de exclusões crescentes e explicitando, pela necessidade do pertencimento, crises e dificuldades de enraizamentos sociais e políticos, culturais e sociais: uma sociedade que tenta conviver com processos de fragmentações crescentes da vida individual e coletiva ao mesmo tempo que com processos político-econômicos de globalização.

É nesse contexto que em especial o tema do sentimento de pertencimento pode ser apontado como se manifestando hoje cada vez mais não só em suas áreas disciplinares de origem, desde a antropologia e a política, mas em outras, como a 
comunicação. Ele se traduz de forma visível, em sentidos e motivações diversos dos de suas origens, sustentando a busca de participação em grupos, tribos e comunidades que possibilitem enraizamento, gerem identidade e referência social, ainda que em territórios tão diversos como os da política, da religião, do entretenimento e da cultura do corpo. Em decorrência, essas buscas suscitam a quebra tradicional de fronteiras entre o local e o global, o público e o privado, o comum e o individual, a comunidade e a sociedade, gerando hibridismos tanto quanto novas formas de tensão e de conflito.

Atente-se que se é instigante reconhecer a atualidade da temática do sentimento de pertencimento, o mesmo podendo ser aplicado às da inclusão e emancipação, é instigante indagar sobre o que os motiva e, sobretudo, sobre o que objetiva o pertencer no contexto de uma sociedade que ao mesmo tempo está em sua causa e é seu objeto de busca. Pertencer a que, incluir-se no que, são indagações importantes fazendo pressupor que a necessidade da busca do pertencimento é tão complexa como a da objetivação que fundamenta essa mesma necessidade.

A temática do sentimento de pertencimento tem ainda sua atualidade e complexidade marcadas pela presença dos meios de comunicação atuando no imaginário social, nas diferentes formas de organização da vida individual e coletiva, na delimitação e criação de interesses que os condicionam. Os diferentes media podem pois, estar atuando como mediação fundamental na construção tanto quanto na caracterização do pertencimento como linguagem desse mesmo processo.

Essas questões se inserem dentro de um objeto de pesquisa mais amplo e já sendo trabalhado como projeto de estudos há algum tempo e que não busca só reconhecer a pertinência do tema do sentimento de pertencimento em comunicação, mas chega a advogar a hipótese de que as práticas de recepção mediática são linguagens expressivas desse mesmo sentimento ${ }^{1}$. $\mathrm{O}$ presente texto, retomando tais questões, problematiza particularmente quanto ao comum que possa estar sendo hoje objetivado na pluralidade e diversidade de manifestações da crise contemporânea de necessidade de pertencimento no âmbito sócio-cultural.

\section{O que motiva o pertencimento: comunidade e sociedade}

Se o tema do pertencimento se vincula ao de comunidade, hoje ambos são retomados em bases ampliadas de significação e tomam características novas na relação assumida desde décadas passadas na distinção entre comunidade e sociedade. $\mathrm{Na}$ verdade, comunidade e sociedade dicotomizaram em décadas recentes formas históricas distintas de compreensão dos processos de socialização, atribuindo-se à primeira a significação nas formas de organização imediata e visível da vida social e cultural e, à segunda, a relação mesmo com a racionalidade que sustenta a estrutura da sociedade. Esses dois contextos na verdade explicitavam uma postura sobre a hegemonia que historicamente foi sendo atribuída à compreensão da estrutura da sociedade, diferentemente da que até então, em fases anteriores da modernidade capitalista coube à organização comunitária da vida social. Daí por que hoje soa muitas vezes estranho e distante o uso do termo pertencimento, sobretudo nas atualizações que vem assumindo, como que descontextualizado historicamente, e soam pertinentes os da inclusão e da exclusão social, ambos se reportando, apesar de proximidades semânticas, a matrizes e tradições históricas e políticas distintas na compreensão das práticas de socialização ora na comunidade, ora na sociedade. As dificuldades na ordem da estrutura social se fazem repercutir na atualidade da esfera da organização imediata da vida social, como que ressurgindo a necessidade das 
comunidades, razão presente na expressão do sentimento de pertencimento.

Mas o conceito de pertencimento, apesar de mantido o termo, tem sua significação ampliada e atualizada na proporção que igualmente assume o de comunidade, especialmente no estabelecimento de novas fronteiras ante o de sociedade. Há uma afirmação de Touraine que pode indicar esse processo de retomada da relação entre pertencimento e comunidade e desta com a sociedade:

"No final do século passado, em plena industrialização do mundo ocidental, os sociólogos nos ensinaram que passávamos da comunidade, fechada em sua identidade global, para a sociedade, cujas funções se diferenciavam e se racionalizavam. A evolução que nós vivemos é quase inversa. Das ruínas das sociedades modernas e de suas instituições saem, por um lado, redes globais de produção, de consumo e de comunicação e, por outro lado, uma volta à comunidade. Vimos ampliar-se o espaço público político; ele não se decompõe sob os efeitos opostos desta tendência à privatização e deste movimento de globalização (Touraine, 1999, 10)."

São essas "ruínas das sociedades modernas e de suas instituições" que motivam a retomada do sentido de comunidade, tanto quanto de pertencimento em dimensões que ultrapassam seus sentidos de origem. Atente-se que, entre outros autores que aprofundam historicamente a presença e a significação de comunidade, em Weber pode-se obter o nexo distintivo entre o subjetivo que motiva o pertencimento ao mesmo tempo que o objetivo, como um interesse, que também está presente nesse processo de construção do sentimento de pertencimento. Para ele, a motivação social que justifica a comunidade está em um "sentimento subjetivo (afetivo ou tradicional) de partícipes de constituição de um todo", enquanto que sociedade tinha sua motivação definida pela "compensação de interesses por motivos racionais (de fins ou valores), ou então numa união de interesses com idêntica motivação" (Weber, 1973, 140).

Vista muitas vezes como uma dimensão de "comunidade emocional" (Martín-Barbero, 2001, 41), a afirmação de Weber destaca que a motivação subjetiva do pertencimento na verdade repousa na busca de "constituição de um todo", ou seja, naquilo que, como um fim, faz do pertencer, um meio e uma necessidade, matriz de algo que se define como um comum.

As fronteiras entre comunidade e sociedade, o mesmo Weber provavelmente já as previa transitáveis quando assegurou que:

"a comunidade pode apoiar-se sobre toda espécie de fundamentos, afetivos, emocionais ou tradicionais. $\mathrm{O}$ conceito de comunidade é deliberadamente muito amplo e abrange situações de fato muito heterogêneas".

$\mathrm{Ou}$ ainda quando assegurou que "a imensa maioria das relações sociais participa em parte da comunidade e em parte da sociedade" (Weber, 1973, 140-143). É

semelhante ao que Touraine assinalara há pouco ao dizer que parte de nós se liga ao espaço público, às normas sociais, outra, ao hedonismo.

Admite-se, pois, que não é difícil apontar que a dimensão subjetiva que motiva o pertencer a um todo é, no caso, o próprio sentimento de pertencimento, acionado de alguma forma pela necessidade já presente nesse todo que é buscado como objetivo-fim. À medida que se amplia esse todo, a visibilidade e a abrangência do objeto-fim, da motivação e da participação, entra-se 
na fronteira de comunidade e de sua relação com o todo social mais amplo definido pela sociedade.

As redes de socialização primária representadas pela família, pela religião, pela etnia, pela educação, bem indicam o âmbito tradicional de comunidade-pertencimento, um todo que agrega, toma visível um contato face a face, a relação de troca de valores, configura a identidade desde a diferença e quase sempre se apoia em bases de territórios não só simbólicos mas físicos: um sentimento de enraizamento tomado visível quase que dimensionando o "tamanho" desse relacionamento. Só existe comunidade quando se expressa o pertencer a esse todo.

Monteiro assinala a dificuldade de se ampliar e ultrapassar o âmbito dessas socializações primárias chegando o "pertencimento às coletividades mais abstratas ...", mais associadas a classes e políticas, no âmbito não mais das formas de organização da sociedade mas das estruturas que as definem, que as fazem distintas tanto quanto opostas (Monteiro, 1996, 104).

Essa dimensão tradicional de pertencimento-comunidade vê-se hoje ampliada desde o objeto-fim que as define e as constituem como um todo: comunidade imaginada, comunidade virtual, comunidade de apropriação, comunidade interpretativa,

comunidades hermenêuticas, sem mencionar inúmeras expressões que as definem através de processos mediáticos como na orkut, nos blogs, tanto quanto nas práticas de movimentos sociais, políticos e culturais, além das redes contemporâneas de relacionamento mediadas por novas tecnologias.

O que Touraine denominou há pouco de "ruínas das sociedades modernas e de suas instituições" talvez possa exemplificar e justificar a razão fundamental para a retomada do sentido de comunidade, como da significação de pertencimento aí envolvida. Primeiro, no contexto mais amplo da própria modernidade ainda hoje vigente. Por outro lado, na expressão da fragmentação da rede de instituições sociais básicas envolvendo a família, a igreja, a escola, bem como o Estado e os partidos, a fragmentação do homem como sujeito e ator social diante de utopias nem sempre materializadas são, entre outras, motivações que sugerem a busca de novas identidades coletivas e individuais que se materializem no espaço visível das relações sociais outras formas de referenciar e coadunar a liberdade com a fluidez de valores e de condições de exercê-la. A perda das referências coletivas e das utopias leva a busca de novas formas de enraizamento e desenraizamento embora na oscilação de compromissos, normas e valores.

Assim, a dimensão simbólica compartilhada em práticas que gerem identificação, se é um traço constitutivo da comunidade, hoje não se vincula necessariamente a territórios físicos delimitados, não se definem em um "tamanho", não pressupõe lugares nem o contato face a face, resguarda-se na materialidade visível de interesses sendo compartilhados e que envolvam participação assegurando-se como linguagem de pertencimento (Paiva, 1998, 68).

Em passado não muito distante, essa relação foi sinalizada pela razão iluminista com possibilidades emancipatórias advindas sobretudo de mudanças estruturais desejadas na produção sócio-econômica, em um contexto histórico da modernidade capitalista e em uma de suas fases mais desenvolvidas e provocativas, graças não só à industrialização emergente, como às promessas advindas do desenvolvimento técnico e cientifico.

Silverstone lembra que:

"as comunidades sempre

tiveram uma composição

simbólica e também material.

Elas são definidas pelas

minúcias da interação

cotidiana, assim como pela

efervescência da ação coletiva

... sem sua dimensão 
simbólica não são nada. Sem seus significados, sem crença, sem identidade e identificação, não há nada: nada a que pertencer, de que participar, nada para compartilhar, promover, e nada para defender" (2002, 185).

Mas é o mesmo Silverstone que lembra que se as comunidades são definidas não só pelo que é compartilhado, mas pelo que é distinguido, a comunidade é "essencialmente uma reivindicação por diferença" (2002, 187), são o exercício da inserção no estar junto social, como exercício da diferença (Hall, 2003, 60) ou mesmo a :diferença como unidade da identidade" (Hall, 1999, 62).

Esse exercício segundo Touraine poderia ser visto como a própria manifestação da constituição do sujeito:

"em um mundo em mudança permanente e incontrolável, o único ponto de apoio é o esforço do indivíduo para transformar experiências vividas em construção de si como ator. A este esforço do indivíduo para ser um ator é que chamo de sujeito, que não se confunde nem com o conjunto da experiência, nem com um principio superior que guiaria o indivíduo e lhe daria uma vocação. O sujeito não tem outro conteúdo que a produção dele mesmo" (Touraine, 1999, 23).

Nesse contexto, perde-se a rigidez de normas e de condições de pertencimento, o enraizamento e o desenraizamento se expressam em processos de mutação constante, chegando-se nessa quebra de fronteiras entre o local e global, o indivíduo e a sociedade, o público e o privado, ao que Bauman $(2003,66)$ atribui is comunidades estéticas, ou seja, a possibilidade de uma natureza superficial, perfünctória e transitória dos laços que surgem entre seus participantes. Se pertencimento também é expressão marcante de uma crise de nossa era, é tanto mais buscado à medida que a sociedade não provê condições de realizá-lo, e identidade e pertencimento se confundem. Expressam um estar junto em crise como se depreende da afirmação de Martín-Barbero:

"Novas maneiras de estar juntos, cuja ligação não provém de um território fixo nem de um consenso racional e duradouro mas da idade e do gênero dos repertórios estéticos e dos gostos sexuais, dos estilos de vida e das exclusões sociais. E que, diante dos tempos longos, mas também de rigidez das identidades tradicionais, amalgamam referentes locais com símbolos de vestuário ou lingüísticas desterritorializados, num redelineamento das fronteiras políticas e culturais que traz à tona o arbitrário artificialismo das demarcações que foram perdendo a capacidade de nos fazer sentir juntos" (2001, 40).

Enfim, a motivação que justifica o pertencer, portanto a identidade se reporta ao que Weber já assinalara quanto à comunidade que, de imediato, justifica-se em fundamentos tanto afetivos, quanto emotivos ou tradicionais "... é deliberadamente muito amplo, e portanto abrange situações de fato muito heterogêneas" (Weber, 1973, 141).

\section{O que objetiva o pertencimento \\ Ainda que sob contextos} conceituais e teóricos distintos termos como "constituição de um todo" (Weber), "identificações coletivas" (Touraine), "vontade comum" (Tönnies, 102), "destino comum" (Telles, 38 e Paiva, 54), e mais usualmente "mundo comum" indicam a objetivação que a relação social expressa como fim, ou seja, a própria razão de ser da comunidade. 
Pressupõe-se, pois, que as dimensões de comum e de público se associam, isto é, há uma objetivação que se coloca como sendo compartilhada e socializada, tomada pública, matriz geradora do sentimento de pertencimento. É uma dimensão de público-comunidade que não se restringe à concepção de Tönnies quando diz que "tudo que é confiante, intimo, que vive exclusivamente junto é compreendido como a vida em comunidade; a sociedade é o que é público, é o mundo. Ao contrário, o homem se encontra em comunidade com os seus desde o nascimento unido a eles como no bem como no mal. Entra-se na sociedade como em terra estrangeira" (Tönnies, 1973, 97).

Talvez a acepção de Silverstone seja aqui ainda mais indicativa: "sonhamos com comunidade ... com o comum e as realidades partilhadas que estão na base dela. Sonhamos com uma vida com os outros, com a segurança de lugar, familiaridade e cuidado ..." (2002, 182).

Se o comum seria o que motiva o estar junto, o que aglutinaria a confluência de olhares e práticas desde o cotidiano, como assinalado por Silverstone, há um bom número de outras questões para a compreensão desse comum aglutinador e que acabam sendo fatores para a sua relativização ou sua percepção ampliada nos dias atuais.

\subsection{O comum enquanto uma} linguagem

A dimensão simbólica

envolvendo valores $\mathrm{e}$ interesses a serem compartilhados, constituindose em linguagem, talvez seja o elemento fundamental que define $\mathrm{o}$ comum. O mundo simbólico a ser compartilhado é a própria representação que gera o comum: "a representação inclui as práticas de significação e os sistemas simbólicos por meio dos quais os significados são produzidos, posicionando-os como sujeito. É por meio dos significados produzidos pelas representações que damos sentido à nossa experiência e àquilo que somos" (Woodward, 2000, 17). A materialidade e a visibilidade com que são publicizados, nem sempre face a face, nem sempre em lugares físicos, mas que gerem identificação, motivem práticas, sintonizem o diverso, talvez seja o elo que motiva o pertencer e envolve o participar. A carência dessas representações traduzidas em símbolos que levem a identificação a um só tempo justificam o sentimento de pertencimento na atualidade e a objetivação aí presente como busca: linguagens que motivam o aglutinar, um mundo comum.

Poder-se-ia questionar se essa busca de um comum coletivo é suficiente para definir o todo que motiva o estar junto. Questionar se essa não é uma perspectiva de visão orgânica da sociedade e da função das partes. É o que se depreende das perspectivas de Park e Burguess (1973, 145) quando indicam:

"embora seja verdade que a sociedade tem esse duplo aspecto, o individual e o coletivo, a suposição deste volume é que a pedra de toque da sociedade, o que distingue uma mera coleção de indivíduos de uma sociedade não é a consciência comum, mas a ação coletiva ... Esta existência de um fim comum é talvez tudo que pode ser legitimamente incluído na concepção 'orgânica' quando aplicada à sociedade".

\subsection{O comum na pluralidade $\mathrm{e}$} diversidade do tempo social

Essa dimensão simbólica sugere que esse comum que agrega, sustentado em valores e interesses compartilhados, se coloca no tempo, isto é, não é fixo, não é permanente, nem como elemento agregador do objeto-fim socializado, nem como motivação enquanto forma, sempre presente para as pessoas. A temporalidade que permeia a vida das pessoas pode ver nesses valores simbólicos, motivos de sintonia ou não, em um certo tempo e não em 
outro. Tanto quanto esses valores simbólicos podem exercer um significado agregador em um tempo, fator de enraizamento sugerido e ao mesmo tempo buscado, como pode não ter a durabilidade de uma significação. A pluralidade da cultura e das temporalidades em sua vivência dão idéia da diversidade com que o comum se realiza na vida social.

Essa mutabilidade presente no comum proposto, tanto quanto na motivação com que é buscado, pode bem apontar o caráter de não permanência das comunidades imaginadas, tanto para elas enquanto comunidades propostas, quanto para os que dela partilham. A atualidade hoje da crise de pertencimento, enquanto objetivações que o motivem, pode estar presente, por exemplo, na crise de identificações culturais apoiadas na concepção de nação, suficientes ontem para agregar como sendo um comum, em seguida insuficiente como fator de identificação.

Para Hall, uma cultura nacional vista como uma comunidade imaginada tem três conceitos ressonantes: as memórias do passado, o desejo por viver um conjunto, a perpetuação da herança $(1999$, 58). A mutação ou erosão desses suportes implica na própria possibilidade da cultura nacional deixar de gerar identificações, portanto pertencimento, propiciando a busca de outros valores aglutinadores. Adorno e Hockheimer apontam sobre essa mutabilidade já na percepção das motivações que justificam o todocomum da própria sociedade: “... a sociedade moderna, como um todo, já deixou de ser acessível à experiência imediata, perceptível em sua totalidade e em suas motivações - no sentido em que poderia sê-lo uma sociedade agrária, pura ou mesmo uma antiga economia corporativa urbana" (1973, 151).

Não é diferente então apontar que essa mutabilidade do tempo social se associa ao que Touraine já assinalara como ligado à crise do próprio contexto da modernidade. Não é igualmente diferente do pensamento de Arendt ao dizer que na modernidade, a perda da religião, das tradições e da autoridade do passado é "equivalente à perda do fundamento do mundo", do se "orientar no mundo," onde "todas as coisas a qualquer momento, podem se tornar praticamente qualquer coisa" (Telles, 1999, 30).

\subsection{O comum envolve a igualdade $\mathrm{e}$ a diferença}

Se o comum como um todo simbólico agregador - étnico, religioso, político, etc - pode ser mutável na temporalidade com que é proposto e visualizado tanto quanto na temporalidade dos que o demandam, ele também envolve necessariamente tanto a identificação que gera a identidade, como a diferença que não o pressupõe agregador.

A alteridade necessária na vida social parte do pressuposto da diversidade que a motiva e que gera a troca entre diversos. Paiva lembra que "o simples estar junto não significa partilhar da experiência do outro, até por que, de acordo com essa perspectiva, não é apenas a proximidade que define. A experiência do outro implicaria uma atitude recíproca de interioridade" (1998, 90). Assim, o reconhecimento do outro, baseado na diversidade dos agentes, é que possibilita a identidade, o olhar de reconhecimento da distinção. Identidade e diferença se compõem como presenças buscantes que formam um comum-comunidade, mas também como indicadores de aceitação de uma comum-comunidade agregador de valor. A identidade é exatamente a necessidade de se posicionar ante o diverso, sobretudo ante o sólido visível em um contexto de instabilidades. Identidadecomunidade levam ao que Bauman chama de necessidade de segurança. A igualdade não se confunde com a aniquilação da diferença, mas apenas acentua que o comum é igual para os que sendo diversos se identificam com esse mesmo comum. A pluralidade se 
mantém com a aceitação da diversidade e não com sua supressão, um enfrentamento desde o comum, e não apesar dele. Na prática, a questão se desloca para a igualdade-justiça (Semprini, 1999, 157-160).

A diversidade, como marca da contemporaneidade, ao mesmo tempo a busca de sua superação, gerariam o que motiva o movimento de enraizamento-desenraizamento que sustenta a necessidade de pertencimento na contemporaneidade. É bem verdade que uma cultura comum na advertência de Williams não é nenhum nível, uma cultura igual, “... uma efetiva comunidade de experiência e sua qualidade depende com igual certeza do conhecimento de uma prática de igualdade entre os cidadãos. Os vários tipos $\mathrm{de}$ desigualdade que ainda dividem a comunidade em que vivemos, tomam difícil ou impossível a comunicação eficaz. Não dispomos de uma genuína experiência comum a não ser em raros e perigosos momentos de crise. Necessitamos de uma cultura comum. Necessitamos dela não para dispor de uma abstração, mas por que não sobrevivemos sem o seu auxilio" (1969, 326).

Essas diferentes conotações que o comum assume trazem na contemporaneidade a presença, como já assinalado, de que ele não é permanente, não é igual, envolve a diferença e que não se coloca como comum único. Aflora-se a questão da monocultura impossível e da convivência com o multiculturalismo, com a diversidade assumindo a marca contestatória, mais na esfera das comunidades do que a globalização acaba propondo na esfera mais ampla da sociedade. Em um mundo marcado pela "ruínas da modernidade de suas instituições", pelo fluxo migratório de valores, de culturas e economias, mestiçagem cultural se confunde com multiculturas. A identidade pode estar na diferença, o comum no diverso, o plural se mostra único como plural.

É nesse sentido que se coloca que a crise de representação que marca a contemporaneidade se desloca desde os ideais da sociedade global para os da comunidade local, em um fluxo nomádico sem um equilíbrio à vista: "uma parte de nós mesmos mergulha na cultura mundial enquanto a outra parte, privada de um espaço público onde se formaria e se aplicariam normas sociais, se fecha no hedonismo ou na busca de pertenças imediatamente vividas" (Touraine, 14). Não é diferente a colocação de Semprini ao afirmar que "é preciso considerar na definição de um espaço público multicultural - a configuração que aí assumem os conflitos sociais e a questão do poder. Os conflitos não se resumem mais exclusivamente na luta pelo controle dos recursos naturais, dos meios de produção, das riquezas, ou mesmo do poder político tradicional. Eles se localizam mais sobre o controle da produção e da distribuição dos significados e dos símbolos sociais" (132). É esse conflito de multiculturas que na verdade busca na esfera local enraizamentos individuais e na esfera social mais ampla geram os conflitos em tomo da sua hegemonia - étnica, política, religiosa, etc - frente a uma economia que se pressupõe suficientemente globalizada e hegemônica para ignorá-los, tanto quanto dominá-los.

A noção generalizada de exclusão, de crise de pertencimento, de ausência de referências sólidas, faz do fluido e do estável sua marca nas acepções de Vattimo (1992) como de Hall (1999).

\section{Recepção mediática e pertencimento: linguagens \\ É de Williams $(1969,322)$ a indicação de que toda teoria da comunicação é uma teoria da comunidade. $\mathrm{O}$ comum que as une é o relacionamento humano, sob diferentes formas e motivações, no tempo e no espaço histórico da vida} social.

Nesse processo de alteridade social, Touraine é incisivo quando assinala que o processo da comunicação não antecede um outro, 
aquele que motiva a própria constituição das pessoas como sujeito:

muitos dão importância primordial à comunicação. Penso, ao contrário, que a relação consigo mesmo preside ao relacionamento com os outros. É um principio não social que preside as relações sociais, de sorte que, depois de um longo período durante o qual se tentou explicar o social somente pelo social, de novo reconhecemos que o social repousa sobre o não social e não se define a não ser pelo lugar que concede ou recusa esta princípio não social que é o sujeito $(1999,84)$.

Talvez se possa afirmar que a comunicação se explicita como fundamento na vida das pessoas exatamente no contexto da experiência de constituição do sujeito. Assim, observa-se que o papel contemporâneo da comunicação tornase cada dia mais reconhecido à medida que a própria sociedade se envolve em condições que, diria Freud (1997), como um mal estar, atuam sobre a experiência de construção do sujeito.

Os processos que delimitam a fragmentação das condições da vida atuando ao mesmo tempo que o processo da globalização na esfera da produção necessariamente possibilitam múltiplas dimensões da crise entre o indivíduo e a sociedade, o sujeito individual e o coletivo, impedindo a sutura dessa fragmentação (Ruiz, 2003). A comunicação hoje, talvez muito mais do que no passado, ainda que se colocando eventualmente de forma hegemônica ante mutações nos quadros das instituições sociais básicas, desenvolve sobretudo um papel de mediação, e por isso mesmo estratégico, e mais, politicamente importante na contemporaneidade, na relação entre as pessoas, e destas com a sociedade.

Vattimo chega a propor que a modernidade, como que assumindo a perspectiva de uma história unitária, termina, e dá lugar á pós-modernidade, exatamente com o advento da sociedade da comunicação generalizada: “... a impossibilidade de pensar a história como um curso unitário ... é também, e talvez mais, o resultado do nascimento dos meios de comunicação de massa" $(1992,10)$.

Esse lugar estratégico dos media na contemporaneidade, configurandolhe de modo especial o papel de mediação, assume diferentes instantes no espaço histórico social, especialmente na relação que faz do pertencimento um significado que na contemporaneidade cada dia mais se evidencia.

A primeira dessas mediações se desenvolve quando os media atuam no mundo simbólico, intermediando valores e interesses, no próprio conteúdo que dá sentido à comunicação. A relação social se estrutura desde a representação que configura esse mundo simbólico e é nele e a partir dele que a materialidade da vida busca sua objetivação, traz demandas individuais e coletivas, exige processos de tensão e de conflitos, tanto quanto de negociação. Há uma afirmação de Martín-Barbero significativa para dar conta desse processo, especialmente sob a ótica da recepção, no quadro dos agentes consumidores atores do processo comunicacional mediático: "... é impossível saber o que a televisão faz com as pessoas se desconhecemos as demandas sociais e culturais que as pessoas fazem à televisão. Demandas que põem em jogo o contínuo desfazer-se e refazer-se das identidades coletivas e dos modos como elas se alimentam e se projetam sobre as representações da vida social que a televisão oferece" $(2001,31)$.

Mediação enquanto espaço de objetivação de demandas, é também espaço de negociação como que indicando presença na construção de um espaço público mediático sustentado na diversidade:

"desde os anos 60, os veículos de comunicação de 
massa e principalmente a televisão têm disponi-

bilizado uma enorme

quantidade de informações

sobre a vida, valores, estilos de vida de grupo que ignoravam tudo ou quase tudo a respeito de outros grupos. Se essa vinculação de informação não homogeneiza as diferenças, ela pelo menos garante sua notoriedade e conscientizou-se de sua existência. Longe de ser simplesmente um espelho, os meios de comunicação tornaram-se um lugar onde se elaboram, se negociam e se difundem os discursos, os valores e as identidades. Ao 'oferecer' uma apresentação multicultural da sociedade, os meios de comunicação contribuem para sua definição" (Semprini, 1999, 123).

Vattimo entende que o nascimento dos media na contemporaneidade é responsável pela percepção da impossibilidade de se pensar o curso da história como unitário, desenvolvendo-se desde então um papel importante na dissolução dos pontos de vista centrais, ou das grandes narrativas, propiciando ao invés de uma massificação das visões de mundo, pensada por Adorno, o contrário, “a explosão e a multiplicação de visões de mundo" $(1992,11)$.

Essas perspectivas que os media assumem enquanto mediação na verdade não se traduzem apenas pelo ângulo supletivo, propositivo de mediações desde necessidades e demandas. É polêmico significar o espaço onde atuam, o que se denomina de espaço público de argumentação de interesses, direitos e deveres do comum social. A dimensão reconhecida de que os media dão visibilidade à pluralidade de visões de mundo não envolve reconhecer que necessariamente também possibilitam seu debate e crítica, constituindo-se em media também enquanto poder, embora segundo perspectivas de chances de resposta às demandas de direitos, desde os da cidadania aos da coletividade.

É bem verdade que há um espaço público que dá visibilidade às questões tornando-as um comum mediático: "o público se configura como o comum", o mundo próprio a todos, o que implica como a própria Arendt já afirmara, que ela seja. ao mesmo tempo "o difundido, o publicitado", entre a maioria (Martín-Barbero, 2001, 44). Essa é a perda de um mundo a que também Arendt se refere no sentido da perda de referências cognitivas e valorativas de um horizonte comum e de uma interlocução possível (Telles, 1999, 38).

Estas considerações apontam que a dimensão de comum, na perspectiva que hoje atualiza o conceito de comunidade, necessariamente também envolve a atualização do comumpúblico, na articulação com o espaço público na contemporaneidade. Estas mesmas considerações sinalizam que a mediação do processo comunicacional hoje talvez mais do que ontem se coloca como fundamental para expressar o diverso e o plural tanto quanto para sinalizar a busca incessante de sua visibilidade, como que redimensionando pelo espaço público mediático, os modos contemporâneos de dominação e negociação do estar junto social, da relação que motiva o eu e o outro, tanto quanto dos conflitos que o sustentam. 


\section{Bibliografia do Artigo}

BAUMAN, Zygmunt. Comunidade, a busca por segurança. Jorge Zahar Editor, RJ, 2003.

FREUD, S. O Mal Estar na Civilização. Ed. Imago, São Paulo, 1997.

HALL, Stuart. Da diáspora, identidades e mediações culturais. Ed. UFMG, Belo Horizonte, MG, 2003. . A identidade cultural na pós-modernidade. Ed.

DP\&A, Belo Horizonte, MG, 1999.

HOCKEIMER, Max, ADORNO, T. W. (org). Temas básicos da sociologia. Ed. Cultrix, SP, 1973.

MARTÍN-BARBERO, Jesus. O medo da mídia. Política, televisão e novos modos de representação. IN: LADISLAU, Dowbor et alii. Desafios da Comunicação. Ed, Vozes, Petrópolis, RJ, 2001.

MIÈGE, B. O espaço público: perpetuado, ampliado e fragmentado. Revista Novos Olhares, n.03, São Paulo, 1999.

MONTEIRO, Paula. Cultura e Democracia no processo de globalização. Revista Novos Estudos Cebrap, n. 44, SP, 1996.

PAIVA, Raquel. O espírito comum: comunidade, mídia e globalismo. Ed. Vozes, Petrópolis, RJ, 1998.

PARK, R. E., BURGUESS, E. W. Comunidade e sociedade como conceitos analíticos. IN: FERNANDES, Florestan. Comunidade e Sociedade, Ed. Nacional e Ed. Da USP, SP, 1973.

RUIZ, Castor Bartolomé. Os paradoxos do imaginário. Ed. Unisinos, São Leopoldo, RS, 2003.

SEMPRINI, Andrea. Multiculturalismo. EDUSC, Bauru, SP, 1999.

SILVERSTONE, Roger. Por que estudar a mídia? Ed. Loyola, SP, 2002.

TELES, Vera. Política e espaço público na constituição do "mundo comum". Notas sobre o pensamento de Hannah Arendt. IN: TELES, Vera. Direitos Sociais. Ed. UFMG, Belo Horizonte, MG, 1999.

TÖNNIES, Ferdinand. Comunidade e Sociedade como entidades típico ideais. IN: FERNANDES, Florestan. Comunidade e Sociedade, Ed. Nacional e Ed. Da USP, SP, 1973. 
TOURAINE, Alain. Poderemos viver juntos? Iguais e diferentes. Ed. Vozes, Petrópolis, RJ, 1999.

VATTIMO, Gianni. A sociedade transparente. Ed. Relógio d’Água, Lisboa, Portugal, 1992.

WEBER, Max. Comunidade e Sociedade como estruturas de socialização. IN: FERNANDES, Florestan. Comunidade e Sociedade, Ed. Nacional e Ed. Da USP, SP, 1973.

WILLIAMS, Raymond. Cultura e Sociedade. Cia Ed. Nacional, SP, 1969.

WOODWARD, K. Identidade e Diferença: uma introdução teórica e conceitual. IN: SILVA, Tomaz Tadeu. Identidade e diferença. Ed. Vozes, Petrópolis, RJ, 2000. 